\title{
Monitoring Re-Suspension and Transport of Dioxin Contaminated Sediment to Evaluate the Recovery of a Shallow Urban Creek Post Sediment Remediation
}

\author{
Lisa Richman, Liad Haimovici, Terry Kolic, Sladjana Besevic, Eric Reiner \\ Ministry of the Environment and Climate Change, Etobicoke, Canada \\ Email: lisa.richman@ontario.ca
}

Received 18 January 2016; accepted 26 February 2016; published 29 February 2016

Copyright @ 2016 by authors and Scientific Research Publishing Inc.

This work is licensed under the Creative Commons Attribution International License (CC BY). http://creativecommons.org/licenses/by/4.0/

(c) (i) Open Access

\section{Abstract}

Pringle Creek, identified as the source of dioxin/furan (PCDD/F) contamination to a Lake Ontario harbour was remediated in 2008. Surface sediment collected in 2013 near the floodplain remediation was no longer contaminated $\left(\sum_{17} \mathrm{PCDD} \backslash \mathrm{Fs}<60 \mathrm{pg} / \mathrm{g} \mathrm{dw}\right)$, but residual contamination extended downstream to the creek mouth (surface sediment maximum: $\sum_{17} P C D D \backslash F s 2900 \mathrm{pg} / \mathrm{g} \mathrm{dw}$ ). Nevertheless, sediment $\sum_{17} \mathrm{PCDD} / \mathrm{F}$ concentrations were lower in 2013 than pre-remediation suggesting that cleaner sediment was being deposited in the creek. Core data confirmed the decrease in sediment contamination through time since the most contaminated sediment was buried. Prior to the development of a remediation strategy for the harbour, the transport of bed-load and suspended sediment contaminated with PCDD/F was assessed. The challenge was the shallow water depth $(0.6 \mathrm{~m})$ throughout the creek thereby requiring non-standard sediment traps designed for this study. Suspended sediment collected in traps in 2014 showed residual contamination at the remediated site $\left(\Sigma_{17} P C D D \backslash F s: 380 \mathrm{pg} / \mathrm{g} \mathrm{dw}\right.$; TEQ (TEF fish) $<0.6 \mathrm{pg} / \mathrm{g}$ ), with concentrations increasing with distance downstream mirroring surface sediment: mean $\sum_{17} \mathrm{PCDD} \backslash F$ s concentration for suspended sediment at the creek mouth was $2200 \mathrm{pg} / \mathrm{g}$ (SD $260 \mathrm{pg} / \mathrm{g} \mathrm{dw}$ ) indicating PCDD/F contributions to the harbour. However, congener patterns in bottom sediment and suspended sediment near the remediated site and extending about $100 \mathrm{~m}$ downstream were similar to background upstream patterns consistent with atmospheric deposition as the source rather than the historical source which indicated that floodplain remedial actions were successful.

\section{Keywords}

Dioxins, Furans, Sediment, Remediation, Contamination 


\section{Introduction}

Contaminant data for Whitby Harbour and Pringle Creek sediment and floodplain soil collected by the Ontario Ministry of Environment and Climate Change (MOECC) from 1993-2013 identified the creek and harbour as being contaminated with polychlorinated dibenzo-p-dioxins and polychlorinated dibenzofurans (PCDD/F). These findings were significant, particularly the presence of high concentrations of the seventeen 2,3,7,8-substituted PCDD/Fs. Since these compounds are bioaccumulative and depending on the congeners present, this can be acutely toxic in fish, wildlife and humans [1] [2]. PCDD/Fs are not intentionally produced but are byproducts of industrial and combustion processes, discharged in waste water from chlorine and chlorinated organic chemical industries or into the atmosphere from the incineration of industrial, municipal, hospital and hazardous waste [2]-[4].

Whitby Harbour is located on the north shore of Lake Ontario with Pringle Creek as the only tributary to the harbour (Figure 1). A detailed survey of the creek in 2000 isolated the source of contamination: the floodplain on both banks of the creek and a privately owned pond connected to the creek. Concentrations of the sum of the 17 toxic individual PCDD/Fs isomers ( $\left.\sum_{17} \mathrm{PCDD} \backslash \mathrm{Fs}\right)$ ranged as high as 190,000 pg/g in the floodplain surface soil (0 - $20 \mathrm{~cm}$ ) (TEQ (toxic equivalent concentrations): 33,000 pg/g) [5], and from $4300 \mathrm{pg} / \mathrm{g}$ to 15,000 pg/g in the surface sediment $(0-10 \mathrm{~cm})$ of the pond (380 to $1100 \mathrm{pg} \mathrm{TEQ} / \mathrm{g})$ [6]. Contamination extended throughout the creek downstream of the pond and into the harbour with $\sum_{17} \mathrm{PCDD} \backslash$ Fs concentrations in the surface sediment ranging up to $130,000 \mathrm{pg} / \mathrm{g}(8500 \mathrm{pg} \mathrm{TEQ} / \mathrm{g})$ based on 2013 data [7]. For comparison $\sum_{17} \mathrm{PCDD} \backslash \mathrm{Fs}$ concentrations for Lake Erie and Lake Ontario ranged from 30 to 10,000 pg/g with a lake wide average TEQ at 19 pg/g to $110 \mathrm{pg} / \mathrm{g}$ respectively [8].

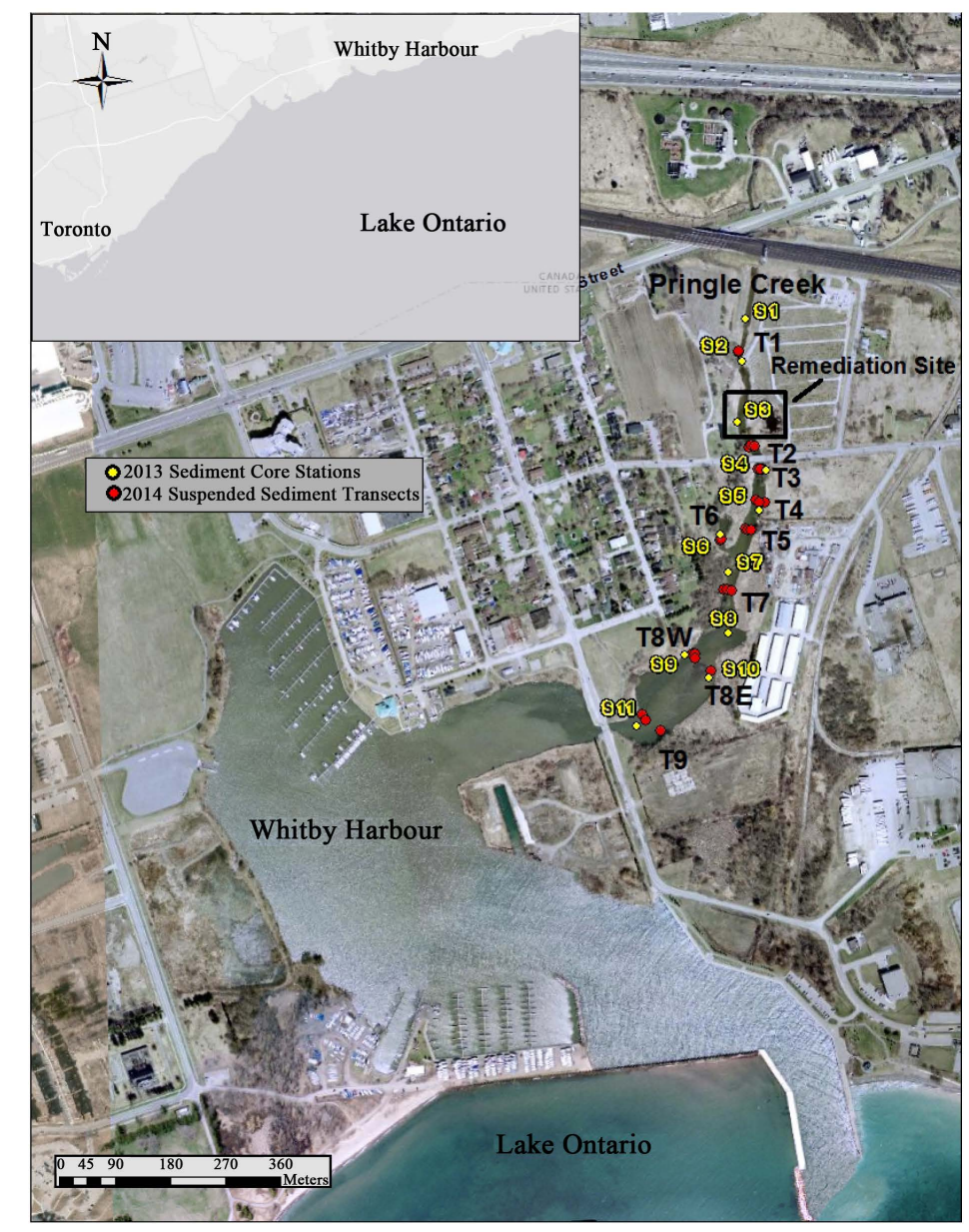

Figure 1.Transect locations (T1-T9) for suspended sediment traps and sediment core samples (S1 to S11) in Pringle Creek. 
Dioxin and furan concentrations are often expressed as TEQs, derived through the use of World Health Organization toxic equivalency factors (TEFs) which express the toxicity to fish, birds or mammals of the different dioxins and furans and dioxin-like PCBs (DLPCBs) on a common basis. Concentrations of the 17 toxic individual PCDD/Fs isomers were converted to toxicity equivalents of 2,3,7,8-TCDD (tetrachlorodibenzo-p-dioxin) using the TEFs for fish and then summed to yield a total TEQ [9]. A comparison of the PCDD/F TEQs from Pringle Creek and Whitby Harbour described above, with the Canadian Sediment Quality Guidelines probable effects limit (PEL) of $21.5 \mathrm{pg}$ TEQ/g [10], designed to assess the potential risk to aquatic life, suggested that adverse effects on biota may be occurring since sediment TEQ concentrations in the pond were up to 50 times greater than the PEL. In addition, juvenile fish PCDD/F tissue concentrations for fathead minnow, creek chub and bluntnose minnow collected from the creek and the harbour ranged up to $34 \mathrm{pg} T E Q / g$ (the highest reported by the MOECC for the province), compared with fish from a reference site (range: <1 pg TEQ/g to $7 \mathrm{pg}$ TEQ/g) [5]. Caged mussels collected from an uncontaminated lake and deployed in the creek and harbour for 21 days confirmed that the PCDD/F were bioavailable: TEQ concentrations in the mussels deployed in the contaminated pond and harbour were $11 \mathrm{pg}$ TEQ/g and $14 \mathrm{pg}$ TEQ/g respectively compared with upstream deployments (TEQ was $<0.01 \mathrm{pg} / \mathrm{g}$ ) [5]. There were restrictions on the consumption of sport fish (Northern Pike, Brown Bullhead, Carp, and White Sucker) due to PCDD/F contamination [11]. A screening level and detailed quantitative ecological risk assessment concluded there was risk to fish, birds and mammals due to the PCDD/F contamination [6] [12]. Based on results from a 2006 Preliminary Quantitative Human Health Risk Assessment [13], remedial action was required due to the high PCDD/F concentrations at the residential property located along the banks of the Creek. In 2008 MOECC remediated the pond and floodplain through its Environmental Clean-up Fund.

A unique congener pattern whereby concentrations of 1,2,3,4,6,7,8-heptachlorodioxin (HpCDD) were higher than octachlorodioxin (OCDD) was displayed in the sediment and soil collected from the floodplain and pond. This was atypical compared with the pattern in sediment collected upstream of the contaminated area which was representative of atmospheric deposition as the source [14]-[16] (Figure 2). Additionally, there was a relatively

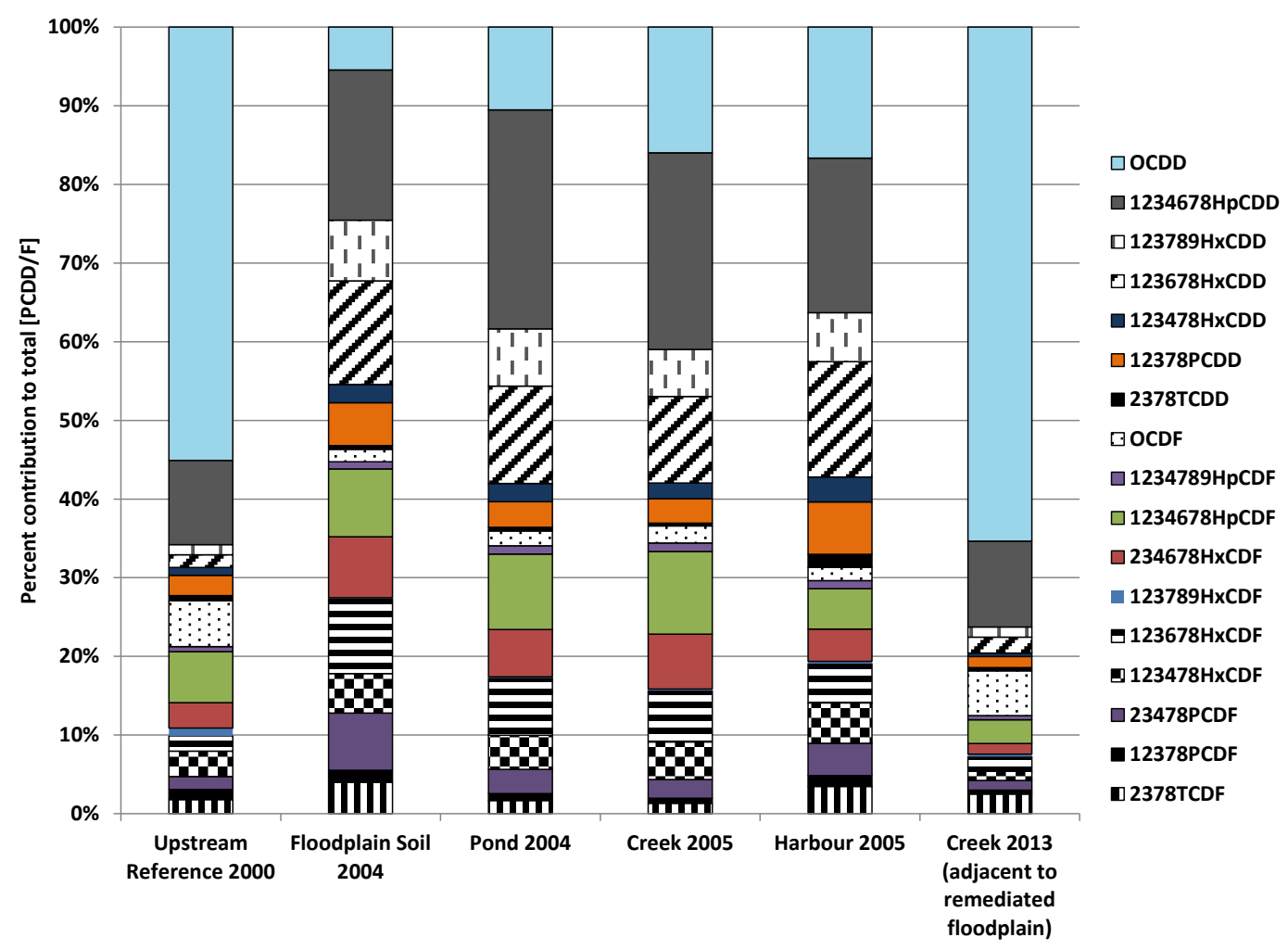

Figure 2. PCDD/F congener pattern in contaminated floodplain soil and sediment collected from the contaminated pond, Pringle Creek and Whitby Harbour prior to remediation compared with the congener pattern in sediment collected at an upstream reference station (2000) and in the creek in 2013 post remediation. Data reflect the percent contribution of each congener to the $\sum_{17} \mathrm{PCDD} \backslash \mathrm{Fs}$. 
higher proportion of 1,2,3,6,7,8-hexachlorofuran (HxCDF), 1,2,3,7,8,9-hexachlorodioxin (HxCDD) and 1,2,3,6,7,8HxCDD compared with the upstream reference stations. This unique congener pattern was instrumental in identifying the source of contamination in the harbour to the contamination at the private property in the creek. Sources typically associated with PCDD/F include waste from chemical industries linked to production of 2,4,5trichlorophenol or pentachlorophenol, or use of the chlorophenol-based fungicides such as Ky-5 [2]-[4]. Accurate identification of the original source of the contamination on the floodplain was not possible, but based on the congener pattern there were similarities to an identified sludge reported in the literature that had been contaminated from treatment of animal hides with phenols/cresols historically used at tanneries as a fungicide (i.e. relatively high proportion of 1,2,3,6,7,8-HxCDD and 1,2,3,4,6,7,8-HpCDD and low proportion of 2,3,7,8-TCDD) [17]. It remains unknown as to how, when and why the contaminated material was deposited on the privately owned property.

Prior to the development of a remediation strategy for the harbour it was essential to understand the re-suspension and transport of sediment from Pringle Creek to ensure that the creek was no longer a significant source of PCDD/F contaminated sediment [18] [19]. Additionally, given the expenditures of the remediation of the floodplain it was important to obtain an estimate of the measure of success and remedy performance [20]. The focus of this paper is a review of the bottom sediment PCDD/F concentrations collected through time to assess natural recovery following the remediation, including a 2014 study to address the transport and contaminant characteristics of suspended sediment downstream of the remediation. Shallow water depth $(<0.6 \mathrm{~m})$ in sections of the creek required non-standard sediment traps. Specialised traps were deployed along 9 transects in the creek to meet these site limitations (Figure 1).

Since the creek was not gauged, current meters, level loggers, and turbidity meters were deployed and water samples were analysed for total suspended solids to estimate discharge rates (flow) and provide data for a model to improve our understanding of sediment transport from the creek to the harbour during storm events and assess backflow from the harbour into the creek [21]. Estimates of mass sediment flux from the creek combined with the contaminant data presented here for the sediment traps could then be applied to the modelling exercises to estimate PCDD/F loadings to the harbour. This information could have implications for sediment remediation strategies [22].

\section{Methods}

\subsection{Sediment Core Sampling}

In 2013 core samples were collected from a boat to assess sediment contamination through time from 11 stations (Stations S 1 to S 11) in Pringle Creek using a hand corer with hammer fitted with hexane rinsed polycarbonate liners (Figure 1). Cores were sectioned into $0-10 \mathrm{~cm}$ sections for the entire length of the core. Sediment samples were submitted for PCDD/F analysis, total organic carbon (TOC), and particle size. Data from the top 10 $\mathrm{cm}$ of sediment collected in 2013 were compared to samples collected in 2005 using the same sampling and analytical methods, and to samples collected in 2000, when grab samples $(0-3 \mathrm{~cm})$ were collected using an Ekman grab sampler, or in circumstances were water was shallow a stainless steel spoon. In all sampling periods, sediment was homogenized in hexane rinsed glassware with a stainless steel hexane rinsed spoon prior to being distributed to appropriate sample containers. All samples were stored in a cooler and on ice until submission to the MOECC Etobicoke laboratory. The general sample composition (e.g. sand, silt etc.), sediment colour, any unusual features, and odours were recorded for each segment of the cores.

\subsection{Suspended Sediment Traps}

Bed-load/suspended sediment traps specifically designed by field staff for this study were deployed at 9 transects (T1 to T9) in Pringle Creek for 6 weeks from May 21/22 until July 15/16 (Figure 1). At each transect 3 traps were deployed to represent flow along the west bank, creek center and east bank (with the exception of transect T8E where due to channel width between the sand bar and the east bank only 1 trap was required). Single $1 \mathrm{~L}$ pretreated sampling bottles (high density polyethylene) were deployed at sites with water depths $<0.6 \mathrm{~m}$ ("lay-down traps"). At those stations, sampling bottles were anchored with a spike, positioned parallel to the shoreline with the bottle opening facing upstream into the current to allow for bed-load and suspended sediment to flow into the bottles. Bottles were supported with rocks collected from the site to maintain their position. At 
deeper sites (typically $0.6 \mathrm{~m}$ to $1 \mathrm{~m}$ ), four $500 \mathrm{~mL}$ sampling bottles were fixed to a patio stone and lowered into the creek. Bottles remained upright perpendicular to the creek bed ("stand-up traps"). All bottles came "cleaned" and ready for sampling by Nalgene. The stainless steel hardware used to frame the stand-up bottles were cleaned in an ultrasonic bath with $\sim 3 \%$ Contrad 70 , rinsed with deionized water, air dried, and hexane rinsed prior to assembling the traps.

Following the six week deployment, bottles were retrieved; the outsides scrubbed clean of algae and organic material, transported to the MOECC Etobicoke, Ontario laboratory and stored upright in a walk-in refrigerator for a minimum of one week to allow the sediment to re-settle. The surface water was decanted and sediment was removed from the bottle and submitted for analysis for TOC, particle size distribution, and PCDD/F analysis. Since only single sampling containers were deployed at the shallow stations the collected sediment was divided for the various analytical procedures. For deeper stations one separate sampling bottle was submitted for TOC and particle size, one bottle for PCDD/F and the remaining bottles were archived. Samples were discarded at some stations where fish (gobies) were present in the bottles and/or sediment was absent (e.g. east bank sample at T1).

\subsection{PCDD/F Analysis}

Surface sediment $(0-10 \mathrm{~cm})$ data reported from 2000 to 2013 were analyzed for PCDD/Fs using MOECC Method E3418 similar to EPA Method 1613 [23]. In brief, sediment samples (3-5 g) were dried and homogenized prior to being extracted overnight via Soxhlet extraction using toluene. Homogenized samples were fortified with ${ }^{13} \mathrm{C}_{12}$-labeled surrogates for each of the 2,3,7,8-substituted PCDD/Fs. Sample extracts were cleaned up to remove bulk co-extractables using a 3 stage classical open column cleanup; an acid/base/silver nitrate impregnated silica column, basic alumina column, and Amoco PX21 carbon/silica column cleanup. As a result there are 2 separate fractions for analysis; Fraction A (mono-ortho-PCBs) and Fraction B (PCDD/Fs and nonortho-PCBs). These 2 fractions were analyzed in separate analytical runs using a GC-HRMS system (gas chromatography-high resolution mass spectrometer) and quantitated using Isotope Dilution. The analyses was carried out on a Waters Autospec HRMS (Waters Corporation, Manchester, UK) with a resolving power of 10,000 coupled to a Hewlett-Packard HP6890 gas chromatograph (Agilent Technologies, Santa Barbara, CA, USA) using a $40 \mathrm{~m}$ DB-5 GC column (0.18 mm i.d., $0.18 \mu \mathrm{m}$ film thickness; J\&W Scientific, Folsom, CA, USA). All PCDD/F data were corrected for surrogate standard recoveries (range: $25 \%$ to $150 \%$ ).

PCDD/F analysis was performed on the 2014 suspended sediment and deeper core segments $(>10 \mathrm{~cm})$ using a new MOECC screening method that utilizes a modified sample preparation procedure involving the QuEChERS technology in conjunction with the analysis being carried out using the same GC/HRMS system stated above and quantitation by isotope dilution [24]. Sediment samples were homogenized by manual mixing. Aliquots of 5 - $10 \mathrm{~g}$ of wet sediment were weighed into $50 \mathrm{~mL}$ centrifuge tubes and fortified with isotopically labelled quantitation standards. After adding $20 \mathrm{~mL}$ of acetonitrile, the samples were vortex-mixed for 10 seconds and placed in an ultrasonic bath for one hour. A ceramic homogenizer, $15 \mathrm{~mL}$ of water, and QuEChERS salts $(6 \mathrm{~g}$ of magnesium sulfate and $1.5 \mathrm{~g}$ of sodium acetate) were added followed by manual shaking for 1 minute. The samples were centrifuged for 5 minutes at 4000 rpm resulting in a separation of the acetonitrile layer.

The acetonitrile layer was pipetted to a clean vial containing $15 \mathrm{~mL}$ of water. The solvent was exchanged into hexanes by liquid-liquid extraction of the acetonitrile-water mixture with three $10 \mathrm{~mL}$ aliquots of hexanes. Cleanup was performed by column chromatography with activated carbon-silica packing. The extracts were passed through the carbon columns followed by a $10 \mathrm{~mL}$ aliquot of $25 \%$ dichloromethane/hexanes. The columns were inverted and the adsorbed analytes were eluted using $10 \mathrm{~mL}$ of toluene which was collected in borosilicate test tubes and evaporated to dryness under a stream of nitrogen. The analytes were quantitatively transferred to GC vials and reconstituted with $20 \mathrm{uL}$ of injection standard for instrumental analysis.

The samples were analyzed using an HP7890 GC coupled to a Micromass Autospec HRMS detector fitted with a DB-5 column (5\% diphenyl, 95\% dimethyl polysiloxane, $40 \mathrm{~m} \times 0.18 \mathrm{~mm}, 0.18 \mathrm{um}$ ) utilizing $40 \mathrm{eV}$ electron ionization in selected ion monitoring mode. The HRMS was tuned daily to a resolution greater than 10,000 (5\% peak height definition). Seven dioxins and ten furans were quantified for each sample. A second $10 \mathrm{~g}$ aliquot of each sample was dried to determine the water content and allow for reporting the results on a dry basis.

To ensure quality assurance and quality control, procedural blanks as well as precision and recovery samples composed of fortified Ottawa sand were included with each set of samples analyzed. Prior to instrumental 
analysis, HRMS sensitivity was verified by confirming that $0.5 \mathrm{pg}$ of 2,3,7,8-tetrachlorodibenzo-p-dioxin (TCDD) injected on-column resulted in a signal to noise ratio greater than 3:1. To verify GC performance, a mixture of TCDD isomers was analyzed before and after each run to confirm that the 2,3,7,8-TCDD peak was separated from its closest neighbors by a valley of no more than $30 \%$. To demonstrate system stability and accuracy, a mid-level calibration standard was analyzed before and after each run to confirm that the observed concentrations were within $20 \%$ of the expected values for the native dioxins/furans and $30 \%$ for the ${ }^{13} \mathrm{C}_{12}$-labelled surrogates.

Both the classical Soxhlet based method and the modified QuEChERS screening method utilize identical GC-HRMS analysis and isotope dilution quantitation under the same analytical conditions. The screening method is considerably faster and greener and was developed for reporting TEQs and yields TEQ results that differ by less than 20\% on average from the classical method (MOECC Method E3418). Accordingly a comparison of TEQ data generated by the two methods was considered reasonable to assess data trends. For actual congener concentrations, the QuEChERS method produces data for heptaCDD that is lower than Method 3418. Accordingly, calculations of $\sum_{17} \mathrm{PCDD} \backslash$ Fs concentrations and congener patterns for the suspended sediments should be interpreted cautiously for the heptaCDD.

\subsection{TOC and Particle Size}

Sediment samples were analyzed for TOC using MOECC method 3142 [25]. Total carbon was determined using a LECO C-632 Carbon Analyzer. Sediment samples were combusted at $1450^{\circ} \mathrm{C}$, then purged with oxygen to oxidize the carbon to $\mathrm{CO}_{2}$. The $\mathrm{CO}_{2}$ was measured by infrared detection. Total inorganic carbon (MOE method 3012) was subtracted from total carbon and the difference is reported as TOC. Particle size was measured using a Coulter LS230 Particle Size Analyzer [26].

\section{Results and Discussion}

\subsection{Surface Sediment $\sum_{17} \mathrm{PCDD} \backslash$ Fs and Total TEQs}

The surface sediment $(0-10 \mathrm{~cm})$ PCDD/F core data showed that contamination remained in the lower section of Pringle Creek (Stations S7 to S11), and in a pond on the west bank (station S6) (Figure 1 \& Figure 3(a)). However, PCDD/F concentrations near the 2008 floodplain remediation were lower than concentrations measured pre-remediation in $2000\left(\sum_{17} \mathrm{PCDD} \backslash \mathrm{Fs}<60 \mathrm{pg} / \mathrm{g}\right.$ vs $660 \mathrm{pg} / \mathrm{g}$ respectively), and were within the range measured in 2000 at 4 upstream locations (range $\sum_{17}$ PCDD $\backslash$ Fs: 24 to $120 \mathrm{pg} / \mathrm{g}$ ) [27]. Additionally, congener patterns for the sediment in this area were now similar to patterns reported upstream rather than the historical source (Figure 2). Although congener patterns maintained the pattern of the historical source further downstream, concentrations of PCDD/F at stations with historical data (collected in 2005), were lower in 2013 than pre-remediation which suggested that cleaner sediment was being deposited (Figure 3(a) \& Figure 4). Furthermore, with only two exceptions (station S5 and S8), the core data confirmed that the most contaminated sediment was buried (Figure 3(b)). TEQs also increased with distance downstream of the remediation site mirroring the $\sum_{17} \mathrm{PCDD} \backslash \mathrm{Fs}$ concentrations and ranged from $28 \mathrm{pg} \mathrm{TEQ} / \mathrm{g}$ to $230 \mathrm{pg}$ TEQ/g (Table 1).

The higher TOC concentrations and percent silt/clay composition in the lower part of the creek compared with sediment adjacent to the remediation site suggested that this area was depositional and may explain in part, the higher concentrations of PCDD/F (Table 1). This is particularly relevant since organic compounds like PAHs, PCBs and PCDD/Fs are hydrophobic and preferentially become associated with the finer particles which typically have higher concentrations of organic carbon [28]-[30]. All PCDD/F data were normalized for TOC but since TOC concentrations were generally similar among all downstream stations, the patterns and gradients of contamination from upstream to downstream remained the same as the non-normalized data, and confirmed that the low concentrations of PCDD/F in the upper part of the creek were due to the remediation and not sediment physical characteristics (Table 1). A comparison of the surface sediment $\sum_{17} \mathrm{PCDD} \backslash$ Fs concentrations up to S5 ( $\leq 250 \mathrm{pg} / \mathrm{g}$ : about $100 \mathrm{~m}$ downstream of the remedial actions), with surface sediment data collected from lakes and rivers that reflect primarily atmospheric inputs suggested that these concentrations do not appear elevated or of concern environmentally (TEQ $\leq 28 \mathrm{pg} / \mathrm{g}$ compared with the CCME PEL of $21.5 \mathrm{pg} / \mathrm{g}$ ). For example, areas in Lake Superior and Lake Huron primarily impacted by atmospheric deposition had total PCDD/F concentrations at <1000 pg/g [31]; Elk River, MN, USA, 700 pg/g [32] and Willamette Basin, OR, USA 400 pg/g [33]. 




(a)
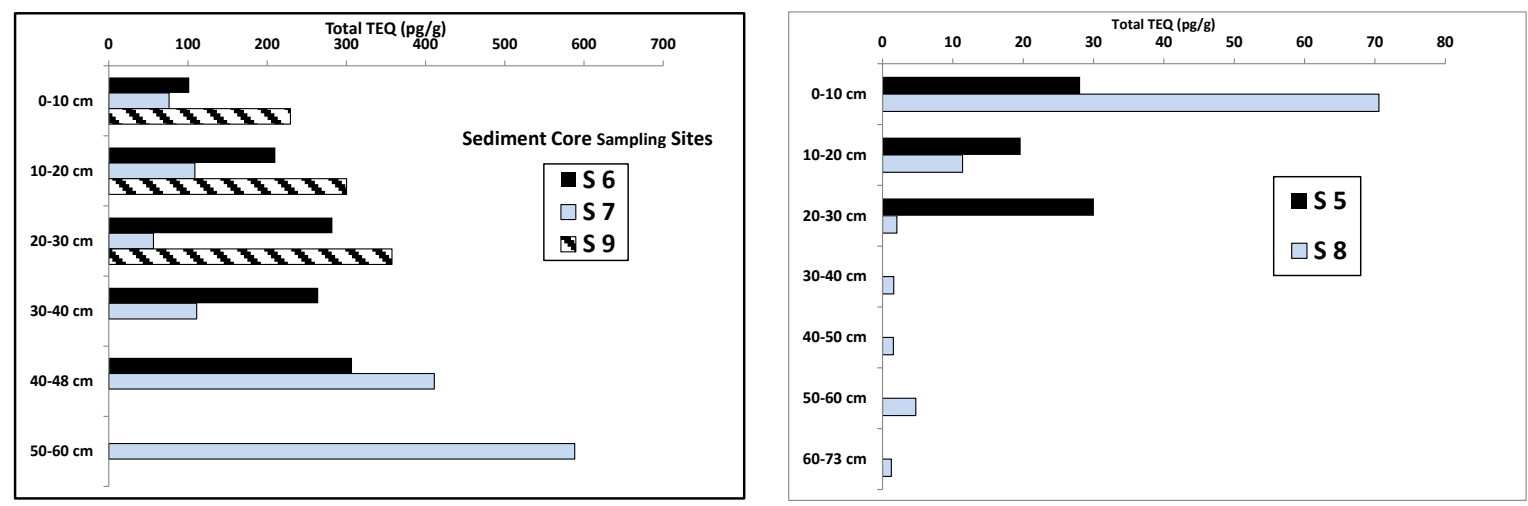

(b)

Figure 3. (a) $\sum_{17} P C D D \backslash F s$ concentrations (pg/g) in sediment cores (surface data: 0 - $10 \mathrm{~cm}$ ) collected in 2005 and 2013 from Pringle Creek (see Figure 1 for station numbers); (b) 2013 Total TEQs (pg/g) for sediment core segments from selected stations in Pringle Creek.

\subsection{Suspended Sediment $\sum_{17} \mathrm{PCDD} \backslash$ Fs and Total TEQs}

Suspended sediment $\sum_{17} \mathrm{PCDD} \backslash$ Fs concentrations in general increased from upstream to downstream where the highest concentrations were present at the creek mouth: $\sum_{17}$ PCDD $\backslash F s$ range 2000 - 2500 pg/g; TEQ 150 to 190 pg/g) (Figure 5). Suspended sediment $\sum_{17}$ PCDD/F concentrations at T2 (190 to 510 pg/g; TEQ 4 - 8 pg/g), located in the vicinity of remediation site were higher than the upstream reference T1 (92 pg/g (SD 40 pg/g); TEQ $<1 \mathrm{pg} / \mathrm{g}$ ) possibly due to residual contamination from the historical source since the floodplain was remediated, but not the creek bed. However, the higher concentrations at T2 were most likely due to the particle size distribution of the samples, and the TOC concentration. TOC and particle size distribution was consistent for sediment trapped within a transect and with the exception of T1, consistent among all transects (Table 2). The 2 traps deployed at the reference station (T1) had the highest percentage of sand particles (63\% and 88\% sand), 




Figure 4. PCDD/F congener pattern in surface sediment $(0-10 \mathrm{~cm})$ collected from Pringle Creek, 2013 compared with the historical source patterns. Data reflect the percent contribution of each congener to the $\sum_{17} \mathrm{PCDD} \backslash \mathrm{Fs}$. $\mathrm{N}=1$ core per station.

Table 1. Percent TOC, particle size characterization, TEQs and $\sum$ PCDD/F normalized for TOC for surface sediment $(0$ - 10 cm) collected from Pringle Creek, 2013.

\begin{tabular}{ccccc}
\hline Station & TOC\% & Silt/Clay $\%$ & TEQ $^{\mathrm{a}}$ pg/g (TEF fish) & Sum PDCC/F pg/g TOC normalized \\
\hline S 1 & 0.8 & 7.4 & 1 & 30 \\
S 2 & 0.6 & 12 & 1 & 53 \\
S 3 & 1.2 & 16 & 2 & 108 \\
S 4 & 1.0 & 62 & 12 & 225 \\
S 5 & 1.1 & 77 & 28 & 356 \\
S 6 & 4.4 & 75 & 100 & 617 \\
S 7 & 1.9 & 44 & 76 & 366 \\
S 8 & 2.6 & 56 & 71 & 1024 \\
S 9 & 2.8 & 49 & 230 & 1124 \\
S 10 & 2.0 & 57 & 170 & 244 \\
S 11 & 0.7 & 7 & 21 & \\
\end{tabular}

${ }^{\mathrm{a} C C M E}$ PEL 21.5 pg/g. 




Figure 5. $\sum_{17} \mathrm{PCDD} \backslash \mathrm{Fs}$ concentrations (pg/g) in sediment traps deployed in Pringle Creek along 9 transects. Concentrations represent the traps deployed within a transect representing the west bank flow, center creek flow and east bank flow.

Table 2. Percent TOC, particle size characertization, TEQs and sum PCDD/F normalized for TOC for suspended sediment.

\begin{tabular}{|c|c|c|c|c|c|c|c|c|c|c|c|c|}
\hline \multirow{2}{*}{ Transect } & \multicolumn{3}{|c|}{ TOC $\%$} & \multicolumn{3}{|c|}{ Silt/Clay \% } & \multicolumn{3}{|c|}{ TEQ $^{\mathrm{C}} \mathrm{pg} / \mathrm{g}$ (TEF fish) } & \multicolumn{3}{|c|}{ Sum PDCC/F pg/g TOC normalized } \\
\hline & West & Center & East & West & Center & East & West & Center & East & West & Center & East \\
\hline $\mathrm{T} 1^{\mathrm{a}}(\mathrm{LDT})^{\mathrm{b}}$ & 1.0 & 0.5 & & 37 & 9 & & 0.6 & 0.5 & & 120 & 126 & \\
\hline $\mathrm{T} 2$ & 2.3 & 2.1 & 2.8 & 83 & 41 & 85 & 6 & 3 & 11 & 189 & 92 & 182 \\
\hline T3 & 2.7 & 2.5 & 2.3 & 71 & 77 & 77 & 6 & 4 & 8 & 147 & 123 & 170 \\
\hline $\mathrm{T} 4$ & 4.5 & 2.9 & 2.9 & 79 & 90 & 92 & 6 & 12 & 18 & 87 & 174 & 203 \\
\hline $\mathrm{T} 5$ & 3.6 & 3.9 & 2.4 & 85 & 91 & 90 & 10 & 24 & 40 & 144 & 160 & 336 \\
\hline T6 (LDT) & 3.2 & 3.2 & 3.4 & 81 & 85 & 81 & 67 & 79 & 88 & 364 & 399 & 391 \\
\hline $\mathrm{T} 7$ & 3.0 & 2.8 & 3.0 & 95 & 92 & 85 & 71 & 52 & 26 & 433 & 358 & 211 \\
\hline T8W & 3.5 & 3.4 & 2.8 & 91 & 89 & 91 & 57 & 51 & 71 & 310 & 299 & 427 \\
\hline T8E (LDT) & & 2.8 & & & 84 & & & 110 & & & 575 & \\
\hline T9 & 3.1 & 3.0 & 2.9 & 87 & 93 & 93 & 153 & 170 & 194 & 638 & 747 & 861 \\
\hline
\end{tabular}

${ }^{a}$ Refers to the transect number and location of sediment trap along the transect representing the west bank, center creek, and east bank flow regimes; bay down trap; ${ }^{\mathrm{c} C C M E}$ PEL 21.5 pg/g. 
and lowest percent TOC (0.5\% and 1.0\%) compared with all the remaining transects. This was not unexpected based on the bottom sediment type which was $>90 \%$ sand and coarse sand (Table 1). Additionally, the traps deployed at T1 were the "lay-down" traps which were more likely to accumulate coarser grained bed-load sediment that was moving downstream. In contrast, with the exception of the center trap at T2 (60\% sand), sediment trapped from T2 toT9 were predominantly described as silt/clay ( $<30 \%$ sand) and TOC ranged from $2.1 \%$ to $4.5 \%$ (mean 3.0\%, SD 0.5\%). A comparison of particle sizes for trapped sediment with bottom sediment showed that the traps selectively collected finer re-suspended sediment as would be expected since these particles are smaller and lighter than sand and require less energy to enter the water column. TEQ concentrations remained less than the PEL as far downstream as T5 (Table 2). Normalizing the data for TOC did not affect contaminant patterns.

The pattern of contamination from T2-T5 tended to show higher concentrations of PCDD/Fs and TEQs in traps deployed along the east bank compared to the west bank. This was not surprising since the highest concentrations of PCDD/Fs at the contaminated site prior to remediation were on the east bank floodplain (Figure 5). This pattern was reversed below T5: traps deployed along the west bank at T7 and T8W, downstream of the pond at T6, collected sediment with higher $\sum_{17} \mathrm{PCDD} \backslash \mathrm{Fs}$ concentrations (range: $1000 \mathrm{pg} / \mathrm{g}-1300 \mathrm{pg} / \mathrm{g}$ ) than T2-T5, and may have reflected movement of suspended sediment from the west bank pond (range: $1200-1300$ $\mathrm{pg} / \mathrm{g}$ ), as well as re-suspension of bottom sediment immediately upstream of T7 since the $\sum_{17} \mathrm{PCDD} \backslash F$ s concentration in bottom sediment collected from station S7 was $1200 \mathrm{pg} / \mathrm{g}$.

The sediment collected in the "lay-down" traps in the west bank pond reflected the higher concentrations of bottom sediment measured in the pond relative to the creek (i.e., Station S6: 1600 pg/g, Figure 3(a)). However, there were difficulties retrieving the traps from that location resulting in disturbance of the bottom sediment. Interestingly, the T7 east bank trap had suspended sediment with concentrations $\left(\sum_{17} \mathrm{PCDD} \backslash \mathrm{Fs}: 630 \mathrm{pg} / \mathrm{g}\right)$ that reflected the upstream flow represented by $\mathrm{T} 5$ rather than the west bank pond (concentrations were about half those measured in the T7 west and center traps). This suggested that the east bank trap was possibly monitoring the movement of the "cleaner" sediment from upstream into the downstream area. The suspended sediment congener patterns discussed below support this hypothesis.

Suspended sediment collected from T8E and T9 at the mouth of the creek had the highest total $\sum_{17} \mathrm{PCDD} \backslash \mathrm{Fs}$ concentrations and TEQs. These values reflected the relatively higher PCDD/F concentrations in bottom sediment in this part of the creek (Figure 3(a)). The current (based on the current meter data collected at the creek mouth) is bi-directional in this part of the creek due to a re-circulation current pattern that develops in the southern part of the creek and seiche induced backwater events from Whitby Harbour and Lake Ontario [21]. Although the prevailing direction is movement from the creek to the harbour, flow moving into the creek from the harbour may also be re-suspending sediment near the creek mouth which can then be trapped at transect T9.

\subsection{Suspended Sediment Congener Patterns}

The congener patterns for all suspended sediment collected as far downstream as T5 were similar to upstream patterns which resembled atmospheric deposition as a source rather than the original source present in the floodplain/pond. This suggested that natural recovery was ongoing, and less contaminated sediment moving from upstream to downstream was likely responsible for the decreases in surface sediment $\sum_{17} \mathrm{PCDD} / \mathrm{F}$ concentration observed post remediation (Figure 6). This pattern change was consistent for both suspended sediment and bottom sediment collected in the vicinity of the remediation. Given that the QuEChERS analytical method used for the suspended sediment analysis was biasing the HpCDD concentrations downward compared to the routine PCDD/F analytical method used for the bottom sediment, the resemblance of the congener pattern to atmospheric deposition in suspended sediment may be exaggerated and must be interpreted with caution. This is particularly true for suspended sediment collected at T7 to T9 where bottom sediment still has a strong signal from the historical source. However, contributions to the total PCDD/F concentrations from other congeners representative of the historical source such as 1,2,3,7,8,9-HxCDD, 1,2,3,6,7,8-HxCDD and 1,2,3,6,7,8-HxCDDF were also consistently changing which provided additional confidence in this trend of improving sediment quality. There were also some subtle differences in congener patterns between and within transects that were noteworthy. A closer look at the individual traps collected from transect T7 showed that the west bank (T7W) and center flow (T7C) traps have congener patterns that reflected suspended sediment at T6 (the west bank pond), reinforcing the possibility of the west bank pond as a source of PCDD/F to downstream areas. The east bank trap at T7 (T7E) had a congener pattern similar to the other transects upstream, specifically T5C (center) and T5E (east bank) (Figure 7). Sediment in the T5W trap had a congener pattern particularly similar to the 


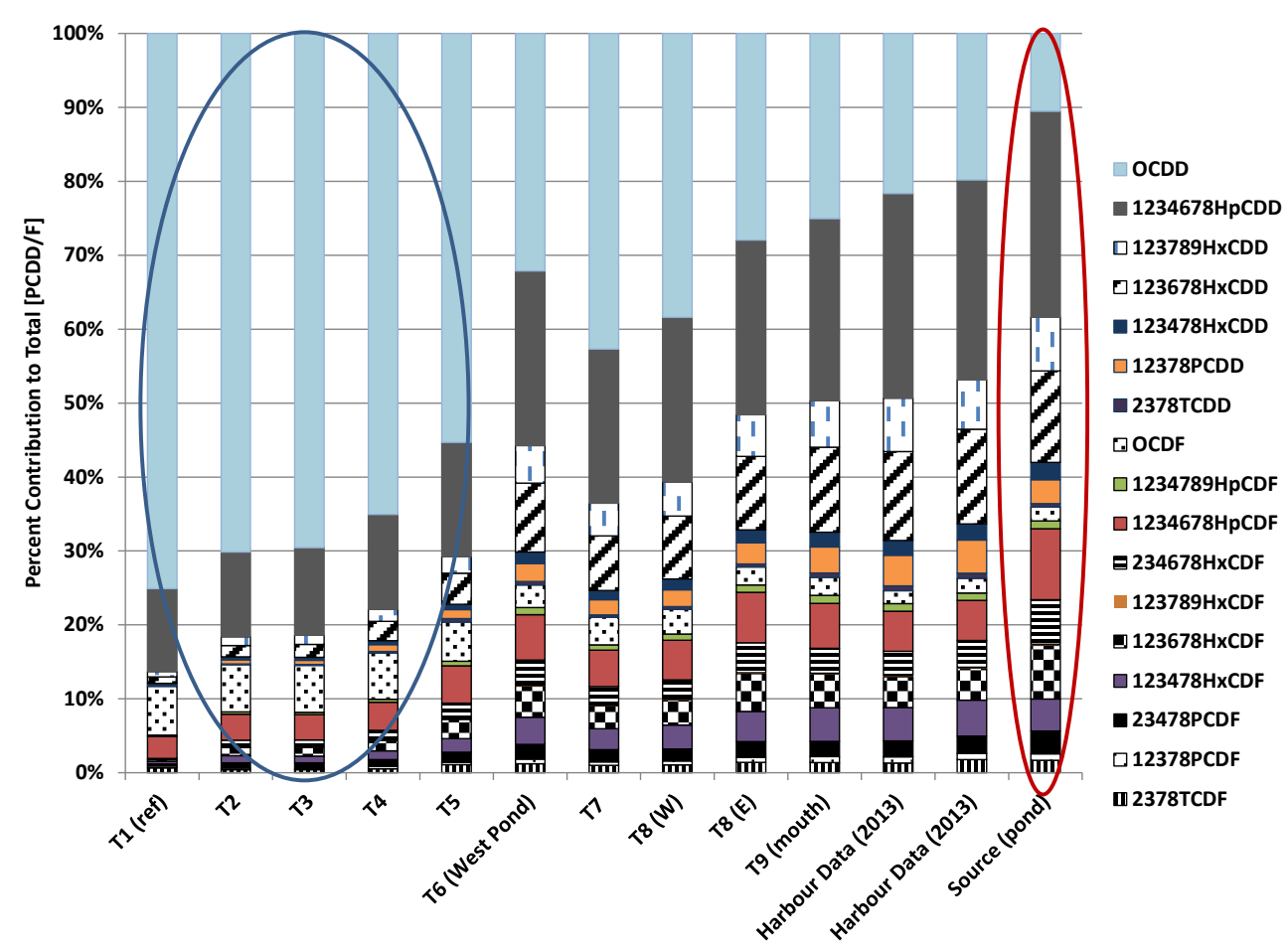

Figure 6. PCDD/F congener pattern in suspended sediment collected in 2014 from sediment traps deployed along transects in Pringle Creek compared with patterns from the upstream reference site, contaminated surface sediment in the harbour and the historical source. Data reflect the mean percent contribution of each congener to the $\sum_{17} P C D D \backslash F s . N=3$ (mean for the three traps located along a transect).

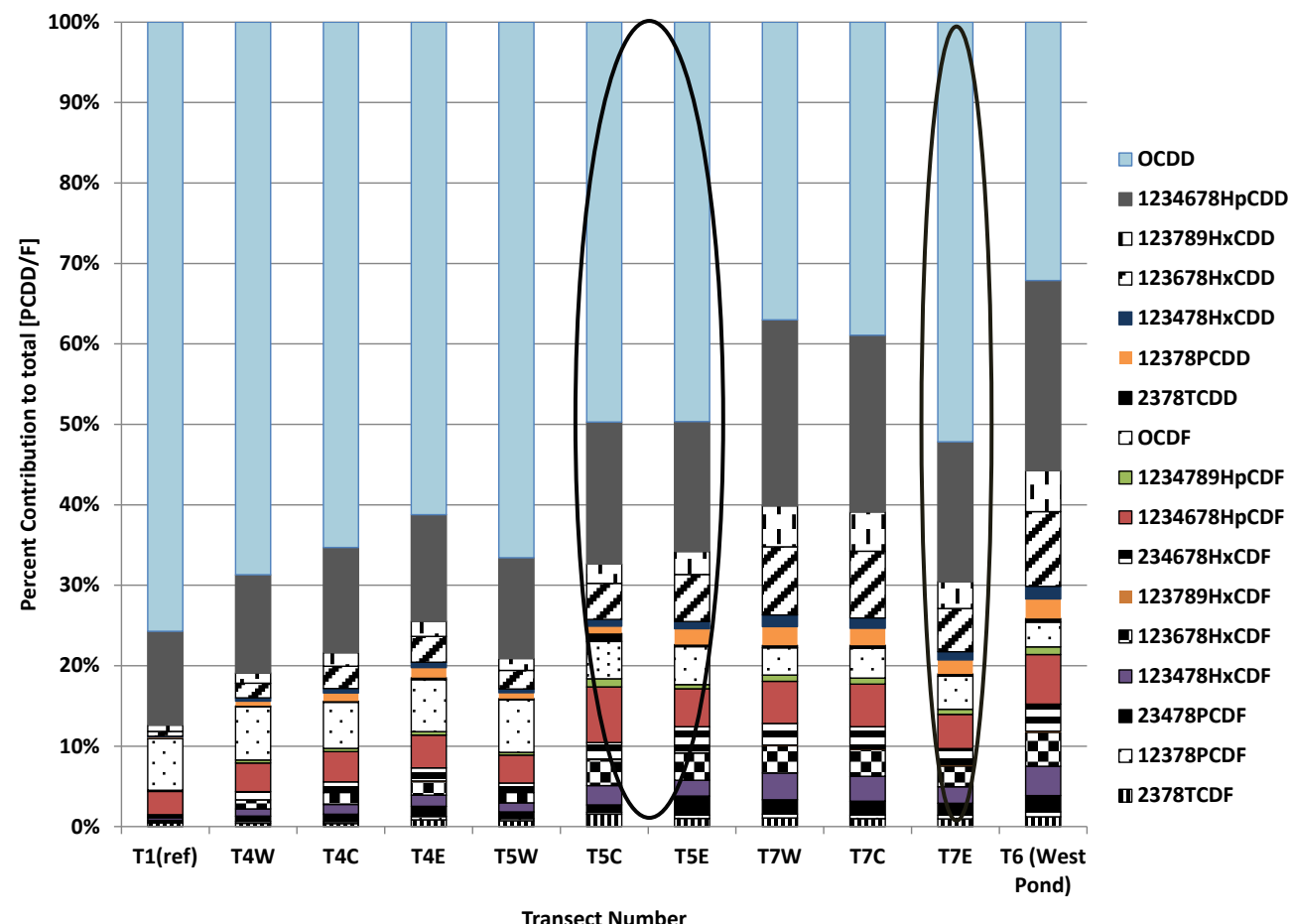

Figure 7. PCDD/F congener pattern in suspended sediment collected from sediment traps deployed along T4 to T7 compared with the reference transect T1 and west bank pond (T6), 2014. W; C; E refer to trap location-west bank; center; east bank respectively. Data reflect the percent contribution of each congener to the $\sum_{17} \mathrm{PCDD} \backslash \mathrm{Fs}$. 
upstream reference stations reinforcing the conclusion that cleaner sediment was moving through the creek. In all cases, TEQs in suspended sediment were lower than the TEQs reported for the bottom sediment at corresponding locations which, notwithstanding the analytical limitations with the congener pattern comparisons, reflected cleaner sediment moving downstream and successful control of the historical source.

\section{Conclusion}

The decrease in $\sum_{17} \mathrm{PCDD} / \mathrm{F}$ concentrations and TEQs in the sediment surface $(0-10 \mathrm{~cm})$ collected post remediation compared with pre-remediation data, as well as core data which showed higher contamination at depth, suggested that the floodplain remediation was successful, and natural recovery was ongoing. Suspended sediment $\sum_{17} \mathrm{PCDD} / \mathrm{F}$ concentrations and TEQs mirrored the bottom sediment patterns; however, the TEQ concentrations were less than those reported for bottom sediment suggesting a dilution effect on re-suspended bottom sediment with less contaminated sediment entering the area from upstream. Congener patterns similar to background upstream patterns consistent with atmospheric deposition as the source rather than the historical source were evident in both bottom sediment and the suspended sediment near the remediated site confirming this assumption. The presence of contaminated bottom sediment and suspended sediment collected in traps in the lower part of the creek and at the mouth suggested that residual PCDD/F contamination is likely being resuspended and entering the harbour. The sediment transport modelling estimates of sediment mass exiting the creek combined with the contaminant data from the sediment traps will be used to estimate contaminant loadings to the harbour [21] and assess the need for remedial actions within the lower section of Pringle Creek.

\section{Acknowledgements}

The author would like to acknowledge John Thibeau, Patrick Padovan and Darcy Fallaise of the Great Lakes Unit, MOECC for the 2014 field work. The efforts of the MOECC Laboratory Services Branch dioxin unit are also acknowledged.

\section{References}

[1] Norstrom, R.J. (2006) Polychlorinated Dibenzo-p-Dioxins and Dibenzofurans in the Great Lakes. In: Hites, R.A. and Hutzinger, O., Eds., Persistent Organic Pollutants in the Great Lakes, The Handbook of Environmental Chemistry, Vol. 5, Spring-Vertag, Berlin Heidelberg, 71-150. http://dx.doi.org/10.1007/698_5_040

[2] Hites, R.A. (2011) Dioxins: An Overview and History. Environmental Science and Technology, 45, 16-20. http://dx.doi.org/10.1021/es1013664

[3] Wenning, R.J., Paustenbach, D.J., Harris, M.A. and Bedbury, H. (1993) Principal Components Analysis of Potential Sources of Polychlorinated Dibenzo-p-Dioxin and Dibenzofuran Residues in Surficial Sediments from Newark Bay, New Jersey. Archives of Environmental Contamination and Toxicology, 24, 271-289. http://dx.doi.org/10.1007/BF01128726

[4] Rappe, C. (1994) Dioxin, Patterns and Source Identification. Fresenius’ Journal of Analytical Chemistry, 348, 63-75. http://dx.doi.org/10.1007/BF00321606

[5] Jones, R. (2007) Dioxins and Furans in Soil from the Pringle Creek Flood Plain Whitby_2006. Report No. PhytoS3029-2006B. Air Monitoring and Reporting Section, Environmental Monitoring and Reporting Branch, Ontario Ministry of Environment.

[6] Richman, L. (2007) Investigation of Dioxin and Furan Contamination in Pringle Creek and Whitby Harbour: 2005 Sediment and Fish Survey and Screening Level Aquatic Ecological Risk Assessment. Water Monitoring and Reporting Section, Environmental Monitoring and Reporting Branch, Ontario Ministry of Environment Technical memorandum, February 2007.

[7] Richman, L. (2014) 2013 Sediment Characterization: Refinement of Spatial Extent of Dioxin/Furan Contamination in Pringle Creek and Whitby Harbour. Environmental Monitoring and Reporting Branch, Water Monitoring and Reporting Section, Ontario Ministry of Environment, Technical memorandum, 22 April 2014.

[8] Shen, L., Gewurtz, S.B., Reiner, E.J., MacPherson, K.A., Kolic, T.M., Helm, P., Brindle, I.D. and Marvin, C.H. (2008) Patterns and Sources of Polychlorinated Dibenzo-p-Dioxins and Polychlorinated Dibenzofurans in Surficial Sediments of Lake Erie and Ontario. Environmental Pollution, 156, 515-525. http://dx.doi.org/10.1016/j.envpol.2008.01.013

[9] Van den Berg, M., Birnbaum, L., Denison, M., De Vito, M., Farland, W., Feeley, M., Fiedler, H., Hakansson, H., Hanberg, A., Haws, L., Rose, Safe, S., Schrenk, D., Tohuama, C., Tritscher, A., Tuomistro, J., Tysklind, M., Walker, N. and Peterson, R.E. (2006) The 2005 World Health Organization Reevaluation of Human and Mammalian Toxic Equi- 
valency Factors for Dioxin and Dioxin-Like Compounds. Toxicological Sciences, 93, 223-241. http://dx.doi.org/10.1093/toxsci/kfl055

[10] CCME (Canadian Council of Ministers of the Environment) (2001) Canadian Sediment Quality Guidelines for the Protection of Aquatic Life, Polychlorinated Dibenzo-p-Dioxins and Polychlorinated Dibenzofurans (PCDD/Fs).

[11] MOE, Ministry of the Environment (2013) Guide to Eating Ontario Sport Fish: 2013-2014. Twenty-Seventh Edition, Revised, Queen's Printer for Ontario.

[12] AECOM (2012) Detailed Quantitative Ecological Risk Assessment for Whitby Harbour, Pringle Creek and the Floodplain. Project Number 60119501.

[13] Dillon Consulting Limited (2006) Pringle Creek Floodplain Preliminary Quantitative Human Health Risk Assessment. File No. 06-6008.

[14] Eitzer, B.D. and Hites, R.A. (1989) Atmospheric Transport and Deposition of Polychlorinated Dibenzo-p-Dioxins and Dibenzofurans. Environmental Science and Technology, 27, 1632-1637. http://dx.doi.org/10.1021/es00045a021

[15] Koester, C.J. and Hites, R.A. (1992) Wet and Dry Deposition of Chlorinated Dioxins and Furans. Environmental Science and Technology, 26, 1375-1382. http://dx.doi.org/10.1021/es00031a015

[16] Pearson, R.F., Swackhamer, D.L., Eisenreich, S.J. and Long, D. (1998) Atmospheric Inputs of Polychlorinated Dibenzo-p-Dioxins and Dibenzofurans to the Great Lakes: Compositional Comparison of PCDD and PCDF in Sediments. Journal of Great Lakes Research, 24, 65-82. http://dx.doi.org/10.1016/S0380-1330(98)70800-7

[17] Agency for Toxic Substances and Disease Registry (2005) Public Health Assessment, Mohawk Tannery Site, Nashua, Hillsborough County, New Hampshire. http://www.atsdr.cdc.gov/HAC/PHA/Mohawk/mts_p1.html

[18] Quesada, S., Tena, A., Guillen, D., Ginebreda, A., Vericat, D., Martinez, E., Navarro-Ortega, A., Batalla, R.J. and Barcelo, D. (2014) Dynamics of Suspended Sediment Borne Persistent Organic Pollutants in a Large Regulated Mediterranean River (Ebro, NE Spain). Science of the Total Environment, 473-474, 381-390. http://dx.doi.org/10.1016/j.scitotenv.2013.11.040

[19] Salo, S., Verta, M., Malve, O., Korhonen, M., Lehtoranta, J., Kiviranta, H., Isosaari, P., Ruokojarvi, P., Koistinen, J. and Vartianinen, T. (2008) Contamination of River Kymijoki Sediments with Polychlorinated Dibenzo-p-Dioxins, Dibenzofurans and Mercury and Their Transport to the Gulf of Finland in the Baltic Sea. Chemosphere, 73, 1675-1683. http://dx.doi.org/10.1016/j.chemosphere.2008.07.085

[20] Bridges, T.D., Gustavson, K.E., Schroeder, P., Ells, S.J., Hayes, D., Nadeau, S.C., Palermo, M.R. and Patmont, C. (2010) Dredging Processes and Remedy Effectiveness: Relationship to the 4Rs of Environmental Dredging. Integrated Environmental Assessment \& Management, 6, 619-630. http://dx.doi.org/10.1002/ieam.71

[21] Nettleton, P.C. (2015) Assessment of Flow and Sediment Transport Characteristic in Pringle Creek. Water Monitoring and Reporting Section, Environmental Monitoring and Reporting Branch, Ontario Ministry of Environment and Climate Change. September 30, 2015.

[22] McLaren, P. and Singer, J. (2008) Sediment Transport and Contaminant Behaviour in the Buffalo River, New York: Implications for River Management. Journal of Coastal Research, 24, 954-968. http://dx.doi.org/10.2112/06-0802.1

[23] Ontario Ministry of Environment, MOE (2008) The Determination of Polychlorinated Dibenzo-p-Dioxins, Polychlorinated Dibenzofurans and Dioxin-Like Polychlorinated Biphenyls (DLPCBS) in Environmental Matrices by Gas Chromatography-High Resolution Mass Spectrometry (GC-MS). (DFPCB-E3418) Laboratory Services Branch, Etobicoke, Ontario.

[24] Ontario Ministry of Environment (MOECC) (2015) A Modified QuEChERS Method for the Determination of Polychlorinated Dibenzo-p-Dioxins and Polychlorinated Dibenzofurans in Sediments by Gas Chromatography-High Resolution Mass Spectrometry (GC-HRMS). (E3535) Laboratory Services Branch, Etobicoke, Ontario.

[25] Ontario Ministry of Environment (MOE) (2008) The Determination of Total Carbon in Soil and Sediments by the Thermal Oxidation and Infrared Detection. CARBONTC-E3142A, Laboratory Services Branch, Etobicoke, Ontario.

[26] Ontario Ministry of Environment (MOE) (2008) The Determination of Particle Size Distribution on Sediments Particulate Matter and Liquids by Coulter Model LS230 Particle Size Analyzer, LLPART-E3328A. Laboratory Services Branch, Quality Management Office, Etobicoke, Ontario.

[27] Richman, L.A. (2004) Great Lakes Reconnaissance Surveys, Water and Sediment Quality Status at Selected Lake Ontario Harbours and Embayments. Water Monitoring Section, Environmental Monitoring and Reporting Branch, Ontario Ministry of Environment.

[28] Cobert, R.L., Webster, G.R.B. and Muir, D.C.G. (1988) Fate of 1,3,6,8-Tertachlorodibenzo-p-Dioxin in an Outdoor Aquatic System. Environmental Toxicology and Chemistry, 7, 167-180.

[29] Lee, S.J., Kim, J.H., Chang, Y.S. and Moon, M.H. (2006) Characterization of Polychlorinated Dibenzo-p-Dioxins and Dibenzofurans on Different Particle Size Fractions of Marine Sediments. Environmental Pollution, 144, 554-561. http://dx.doi.org/10.1016/j.envpol.2006.01.040 
[30] Schwientek, M., Rugner, H., Beckingham, B., Kuch, B. and Grathwohl, P. (2013) Integrated Monitoring of Particle Associated Transport of PAHs in Contrasting Catchments. Environmental Pollution, 172, 155-162. http://dx.doi.org/10.1016/j.envpol.2012.09.004

[31] Shen, L., Gewurtz, S.B., Reiner, E.J., MacPherson, K.A., Kolic, T.M., Khurana, V., Helm, P.A., Howell, E.T., Burnistorn, D.A., Brindle, I.D. and Marvin, C.H. (2009) Occurrence and Sources of Polychlorinated Dibenzo-p-Dioxins, Dibenzofurans and Dioxin-Like Polychlorinated Biphenyls in Surficial Sediments of Lakes Superior and Huron. Environmental Pollution, 157, 1210-1218. http://dx.doi.org/10.1016/j.envpol.2008.12.012

[32] Reed, L.W., Hunt, G.T., Maisel, B.E., Hoyt, M., Keefe, D. and Hackney, P. (1990) Baseline Assessment of PCDDs/ PCDFs in the Vicinity of the Elk River, Minnesota Generating Station. Chemosphere, 21, 159-171. http://dx.doi.org/10.1016/0045-6535(90)90388-A

[33] Bonn, B.A. (1998) Sources of Dioxins in the United Kingdom: The Steel Industry and Other Sources. Chemosphere, 46, 371-381. 